The FASEB Journal express article 10.1096/fj.04-3424fje. Published online March 22, 2005.

\title{
Evidence for a functional role of the second C5a receptor C5L2
}

Hongwei Gao,* Thomas A. Neff,* Ren-Feng Guo,* Cecilia L. Speyer,* J. Vidya Sarma,* Scott Tomlins, ${ }^{*}$ Yunfang Man, ${ }^{*}$ Niels C. Riedemann,${ }^{\dagger}$ L. Marco Hoesel, ${ }^{*}$ Ellen Younkin, ${ }^{*}$ Firas S. Zetoune, ${ }^{*}$ and Peter A. Ward*

*Department of Pathology, University of Michigan Medical School, Ann Arbor, Michigan 48109; and 'Department of Trauma Surgery, University of Hannover Medical School, Hannover 30625, Germany

Corresponding author: Peter A. Ward, M.D., Department of Pathology, University of Michigan Medical School, 1301 Catherine Road, Ann Arbor, Michigan 48109-0602. E-mail:

pward@umich.edu

\section{ABSTRACT}

During experimental sepsis in rodents after cecal ligation and puncture (CLP), excessive C5a is generated, leading to interactions with $\mathrm{C} 5 \mathrm{aR}$, loss of innate immune functions of neutrophils, and lethality. In the current study, we have analyzed the expression of the second C5a receptor C5L2, the putative "default" or nonsignaling receptor for C5a. Rat C5L2 was cloned, and antibody was developed to C5L2 protein. After CLP, blood neutrophils showed a reduction in C5aR followed by its restoration, while C5L2 levels gradually increased, accompanied by the appearance of mRNA for C5L2. mRNA for C5L2 increased in lung and liver during CLP. Substantially increased C5L2 protein (defined by binding of ${ }^{125} \mathrm{I}$-anti-C5L2 IgG) occurred in lung, liver, heart, and kidney after CLP. With the use of serum IL-6 as a marker for sepsis, infusion of anti-C5aR dramatically reduced serum IL-6 levels, while anti-C5L2 caused a nearly fourfold increase in IL6 when compared with CLP controls treated with normal IgG. When normal blood neutrophils were stimulated in vitro with LPS and C5a, the antibodies had similar effects on release of IL-6. These data provide the first evidence for a role for C5L2 in balancing the biological responses to C5a.

Key words: cecal ligation and puncture • IL-6

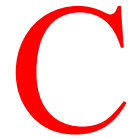

5a is a complement-derived anaphylatoxin containing 74 amino acids and exerts various proinflammatory effects such as chemotactic responses of neutrophils, release of granular enzymes from phagocytic cells, production of superoxide anion in neutrophils, histamine release from mast cells, vasodilatation, increased vascular permeability, and smooth muscle contraction (1-7). Excessive production of C5a occurs early in sepsis and leads to an unregulated proinflammatory response, ultimately resulting in multi-organ failure and tissue damage $(1,2,8)$. In particular, innate immune functions of neutrophils, including chemotaxis, phagocytosis, and $\mathrm{H}_{2} \mathrm{O}_{2}$ production, are severely impaired (9-11). C5a blockade during both LPS- and cecal ligation and puncture (CLP)-induced sepsis was protective in rodents such as monkeys and rats. 
Blockade of C5a greatly reduced appearance of multi-organ failure in CLP rats $(8,10,12,13)$. These data suggest that increased generation of C5a plays an important role during the development of sepsis, compromising crucial innate-immune functions.

The effects of $\mathrm{C} 5 \mathrm{a}$ are mediated by its binding to its receptor, $\mathrm{C} 5 \mathrm{a}$ receptor (C5aR, CD88), which is a $\mathrm{G}$ protein-coupled seven-transmembrane spanning receptor $(14,15)$. Expression of $\mathrm{C} 5 \mathrm{aR}$ has been found on a variety of cells in many different organs and cells, including epithelial cells, endothelial cells, myeloid cells, and T cells (16-23). During sepsis, vascular expression of C5aR is dramatically increased in lung, liver, kidney, and heart as a function of time (24). In addition, C5aR mRNA level is also elevated in all of these organs (24). Blockade of C5aR with antibody or a small molecular inhibitor $(\mathrm{C} 5 \mathrm{aRa})$ in CLP mice has been shown to greatly improve survival $(24,25)$, suggesting that the protective effects of C5a blockade were due to interception of $\mathrm{C} 5 \mathrm{a} / \mathrm{C} 5 \mathrm{aR}$ signaling.

Since its identification in early 1990, C5aR appeared to be the sole receptor for C5a. Recently, a second receptor for C5a, C5L2, has been described (26-29). C5L2 is a high affinity receptor for both C5a and C5a des arg, and its expression on the human peripheral neutrophils is at levels similar to C5aR (26). Like C5aR, C5L2 has an acidic ligand binding N-terminal domain and a ligand activation domain (28). In contrast to C5aR, C5L2 is not coupled to intracellular G protein signaling pathways, possibly because of the substitution of Leu for Arg in the DRY sequence at the end of the third transmembrane segment and a shorter third intracellular loop lacking in Ser/Thr residues. When transfected into several cell lines, C5L2 is weakly phosphorylated after C5a binding and does not initiate increased calcium influx, stimulate chemotaxis, or activate MAP kinase $(26,28)$. Furthermore, in contrast to C5aR, C5a binding to C5L2 does not appear to result in internalization of the complex and demonstrates slow ligand on and off rates $(26,28)$. Such findings suggest that C5L2 may act as an unproductive, decoy, or scavenger receptor for C5a.

Given the importance of $\mathrm{C} 5 \mathrm{a} / \mathrm{C} 5 \mathrm{aR}$ signaling during sepsis in rodents, it was important to explore the function of C5L2 in sepsis. We cloned rat C5L2 and investigated expression of C5L2 on surfaces of rat neutrophils and organs (lung, liver, kidney, heart) during sepsis, using in vivo binding studies with ${ }^{125}$ I-anti-C5L2 antibody ( $\alpha$ C5L2) and real-time PCR analysis for mRNA of C5L2. In addition, we explored the effects of $\alpha$ C5L2 treatment on both in vitro and in vivo expression of IL-6. Our findings show for the first time that C5L2 is up-regulated during sepsis and that C5a interaction with C5L2 is negatively correlated with levels of expressed IL-6. This suggests that $\mathrm{C} 5 \mathrm{aR}$ and $\mathrm{C} 5 \mathrm{~L} 2$ compete for $\mathrm{C} 5 \mathrm{a}$ binding, the balance determining inflammatory mediator production.

\section{MATERIALS AND METHODS}

\section{Peptide synthesis and production of anti-mouse C5aR and C5L2 antibodies}

A 37-amino acid peptide spanning the $\mathrm{N}$ terminus of the mouse C5aR (MDPIDNSSFEINYDHYGTMDPNIPADGIHLPKRQPGDC) and a 38-amino acid peptide spanning the $\mathrm{N}$ terminus of the mouse C5L2 (MMNHTTSEYYDYEYDHE HYSDLPDVPVDCPAGTCFTSD) were synthesized as described previously (21). The peptides were coupled to keyhole limpet hemocyanin by the glutaraldehyde method and used for the immunization of rabbits and the production of 
immunoreactive anti-sera. The anti-peptide-specific antibody was either IgG-purified using ImmunoPure (A/G) IgG purification kit or affinity-purified using Aminolink plus immobilization kit by coupling the synthetic peptide to agarose support (Pierce, Rockford, IL) and was characterized by ELISA, flow cytometry, and Western blots for both mouse and rat C5L2.

\section{Cloning and expression of rat C5a}

Recombinant rat $\mathrm{C} 5 \mathrm{a}$ was produced in our laboratory, using the pGEX expression vector for GST gene fusion (Amersham Pharmacia Biotech) (9).

\section{Cloning of full-length rat $\mathrm{C} 5 \mathrm{~L} 2$}

The full coding sequence of rat $\mathrm{C} 5 \mathrm{~L} 2$ was cloned from rat lung. Based on mouse $\mathrm{C} 5 \mathrm{~L} 2$ sequence, two deoxyoligonucleotides were designed (5'-GCTCGG CCGCTCGAGACCATGGACAACCACACCACCAGC-3' and 5'-CCGAAACCGGA ATTCCACCGGCATCTCAGA-3') and used to amplify a PCR product containing a portion of the rat $\mathrm{C} 5 \mathrm{~L} 2$ cDNA. The sequence at the $5^{\prime}$ end of the cDNA was obtained by $5^{\prime}-\mathrm{RACE}$ PCR (Invitrogen). The sequence at the $3^{\prime}$ end of the cDNA was obtained by a BLAST search of the NCBI Rat EST database (dbEST 14223745).

\section{Northern blot analysis}

Multiple tissue blots containing $\sim 2 \mu \mathrm{g}$ of poly (A) mRNA per lane (BD, Clontech) were sequentially hybridized with random primer ${ }^{32} \mathrm{P}$-labeled cDNAs spanning the coding regions of rat $\mathrm{C} 5 \mathrm{~L} 2, \mathrm{C} 5 \mathrm{aR}$, and actin.

\section{Transient expression of rat C5L2 in HEK293 cells}

HEK 293 cells were transiently transfected with pcDNA3.1C5L2 by Lipofectamine 2000. Fortyeight hours after transfection, cells were used for immunostaining.

\section{Immunocytochemistry and confocal microscopy}

Rat C5L2-transfected HEK 293 cells or isolated rat blood neutrophils were fixed in 4\% paraformaldehyde, and indirect immunofluorescence was performed as described previously (9). Anti-C5aR $(\alpha \mathrm{C} 5 \mathrm{aR})$ or $\alpha \mathrm{C} 5 \mathrm{~L} 2(10 \mu \mathrm{g} / \mathrm{ml})$ was visualized with $15 \mu \mathrm{g} / \mathrm{ml}$ of goat anti-rabbit IgG conjugated to Alexa 568 (Molecular Probes). Cells were imaged using a confocal microscope (Olympus FV 500, Japan). No signal was detected in mock-transfected HEK 293 cells (data not shown).

\section{Rat model of CLP}

Male Long-Evans specific-pathogen-free rats (275-300 mg; Harlan, Indianapolis, IN) were used. After intraperitoneal administration of ketamine $(20 \mathrm{mg} / 100 \mathrm{mg}$ body wt.), the cecum was identified and ligated below the ileocecal valve. The cecum was then subjected to a single through-and-through perforation with an 18 gauge needle. After the bowel was repositioned, the abdomen was closed in layers, using a 4.0 surgical suture and metallic clips (Ethicon, 
Somerville, NJ). Sham animals underwent the same procedure except for CLP. Before and after surgery, animals had unlimited access to food and water.

\section{Flow cytometric analysis}

C5aR or C5L2 content on blood neutrophils was evaluated by indirect immunofluorescence staining of whole blood using an established lyse/wash procedure (BD PharMingen). Flow cytometric analysis was carried out immediately after blood collection. One hundred microliters of rat whole blood were first incubated with $1 \mu \mathrm{g}$ rat Fc Block (BD PharMingen) for 15 min and then stained with $20 \mu \mathrm{l}$ of $\alpha \mathrm{C} 5 \mathrm{aR}$ or $\alpha \mathrm{C} 5 \mathrm{~L} 2$ for $30 \mathrm{~min}$. After being washed, the cells were labeled with Fluorescein Isothiocyanate (FITC)-conjugated goat anti-rabbit IgG (1:50) (Biosource, Santa Clarita, CA). Erythrocytes were lysed for $10 \mathrm{~min}$ by addition of $1 \times$ fluorescent activated-substrate conversion (FASC) lysing solution (BD PharMingen). After being washed, the leukocytes were resuspended in a fixation solution (1\% paraformaldehyde in PBS with $0.1 \%$ sodium azide). Granulocytes were gated by the typical forward and side light scatterprofiles. The same-gated population has been proven to be granulocytes by staining of whole blood with a FITC-labeled rat granulocyte marker, HIS48 (BD PharMingen) (9).

\section{Neutrophil isolation from rat whole blood and in vitro stimulation}

Whole blood from rats was drawn from the inferior vena cava into syringes containing the anticoagulant citrate dextrose (ACD; Baxter Health Care, Deerfield, IL). Neutrophils were isolated using Ficoll-Paque gradient centrifugation (Pharmacia Biotech, Uppsala, Sweden) followed by dextran sedimentation. Residual red blood cells were lysed using $\mathrm{NH}_{4} \mathrm{Cl}$ lysis buffer. Neutrophils were then resuspended in Dulbecco's modified Eagle medium (DMEM) containing 10\% fetal bovine serum. For IL-6 study, neutrophils were first incubated with either $1 \mu \mathrm{g} \alpha \mathrm{C} 5 \mathrm{aR}$ or $\alpha \mathrm{C} 5 \mathrm{~L} 2$ at $37^{\circ} \mathrm{C}$ for $1 \mathrm{~h}$ and then stimulated with LPS $(20 \mathrm{ng} / \mathrm{ml})$ and C5a $(10 \mathrm{nM})$ for $4 \mathrm{~h}$. Supernatant fluids were collected after pelleting of the cells and were frozen at $-80^{\circ} \mathrm{C}$ until used for ELISA analysis.

\section{RT-PCR analysis for C5L2 and C5aR}

Total RNAs from rat blood neutrophils at different stages of sepsis were isolated with the Trizol method (Life Technologies, Rockville, MD) according to the manufacturer's instructions. Digestion of any contaminating DNA was achieved by treatment of samples with RQ1 Rnasefree DNase (Promega, Madison, WI). Reverse transcription was performed with $0.5 \mu \mathrm{g}$ RNA using the Superscript II RNase $\mathrm{H}^{-}$Reverse Transcriptase (Gibco-BRL, Grand Island, NY) according to the manufacturer's protocol. PCR was then performed with primers for C5aR: 5' primer, 5'TATAGTCCTGCCCTCGCTCAT-3' and 3' primer, 5'-TCACCACTTTGAGCGTCTTGG-3'; C5L2: 5' primer, 5'-GCCTACCTCATAGT CCTGCT-3' and 3' primer, 5'-CAGTGGTGATGGTAACTTCC-3'. The primers for the "housekeeping" gene GAPDH were 5' primer, 5'-GCCTCG TCT CAT AGA CAA GAT G-3' and 3' primer, 5'-CAG TAG ACT CCA CGA CAT AC-3'. After a 'hot-start" for 5 min at $94^{\circ} \mathrm{C}, 30$ cycles were used for amplification with a melting temperature of $94^{\circ} \mathrm{C}$, an annealing temperature of $60^{\circ} \mathrm{C}$, and an extending temperature of $72^{\circ} \mathrm{C}$, each for $1 \mathrm{~min}$, followed by a final extension at $72^{\circ} \mathrm{C}$ for $8 \mathrm{~min}$. The RT-PCR product was confirmed by electrophoresis of samples in $1.2 \%$ agarose gel. Control experiments were performed with the samples in which reverse transcriptase was not added to rule out contaminating DNA being responsible for any results. 


\section{Experimental CLP-induced sepsis in mice and organ preparation}

Seven- or eight-week-old specific pathogen-free male C57BL/6 mice were used. Approximately two-thirds of the cecum was ligated through a $1.5-\mathrm{cm}$ abdominal midline incision. The ligated part of the cecum was punctured through and through with a 21 gauge needle. For the death of the animals, the inferior vena cava was incised and $\sim 500 \mu \mathrm{l}$ of blood were withdrawn. The chest was then opened, and the pulmonary artery was slowly perfused with $60 \mathrm{ml}$ DPBS, the perfusion liquid being allowed to leak out of the open inferior vena cava after perfusion. Perfusion quality was optically controlled by observing the organ color change (to white) as the blood was completely removed. Thereafter, organs were removed for radioactivity analysis or snap-frozen for real-time PCR experiments.

\section{In vivo binding studies}

In vivo binding studies are described elsewhere (24). Briefly, $100 \mathrm{ng}$ of ${ }^{125} \mathrm{I}$-labeled $\alpha \mathrm{C} 5 \mathrm{aR}$ or $\alpha \mathrm{C} 5 \mathrm{~L} 2$ antibody and $2 \mu \mathrm{g}$ of nonlabeled antibody as carrier in a total volume of $200 \mu \mathrm{lBS}$ were injected intravenously $15 \mathrm{~min}$ before death. Immediately after euthanization, lung, liver, kidney, and heart were thoroughly perfused and weighed. C5aR or C5L2 antibody binding was determined by using a gamma counter (1261 Multi; Wallac, Gaitherburg, MD) and expressed as counts per min (CPM) per gram tissue.

\section{Detection of C5aR/C5L2 mRNA in various organs during sepsis by SYBR green real-time quantitative PCR analysis}

Organs from mice were obtained $0,3,6$, and $12 \mathrm{~h}$ after induction of CLP and prepared as described above. Total RNA was isolated with the Trizol method. Digestion of any contaminating DNA was achieved by treatment of samples with RQ1 RNase-Free DNase. Reverse transcription was performed with $1 \mu \mathrm{g}$ RNA using the Superscript II RNase H Reverse Transcriptase. SYBR green real-time quantitative PCR was then performed with primers for C5aR: $5^{\prime}$ primer, 5'-GAAGCGGCAACCTGGGGATGT-3' and $3^{\prime}$ primer, 5' CGTCTGGCTC GAAGGCTGTCAC-3'; C5L2: 5' primer, 5'-CTGGGCCTCTTGCTGACTGTGC-3' and 3' primer, 5'GCCCCAGGAAGCCAAAGAGGA-3'; GAPDH: 5' primer, 5' TACCCCCAATGTGTCCGTCGTG3' and 3' primer, 5'-CCTTCAGTGGGCCCTC AGATGC-3'.

\section{Detection of IL-6 in mouse serum by ELISA}

Blood was drawn from $\alpha \mathrm{C} 5 \mathrm{aR}, \alpha \mathrm{C} 5 \mathrm{~L} 2$, and control IgG-treated mice $6 \mathrm{~h}$ after CLP. The blood was allowed to clot on ice for $2 \mathrm{~h}$ before serum was obtained by centrifugation. Serum samples were subsequently analyzed for IL-6 using ELISA kits (BioSource International, Camarillo, CA) according to the manufacturer's instructions.

\section{Statistical analysis}

All values were expressed as the means \pm SE. Significance was assigned where $P<0.05$. Data sets were analyzed using Student's $t$ test or one-way ANOVA, with individual group means being compared with the Student-Newman-Keuls multiple comparison test. 


\section{RESULTS}

\section{5'-RACE PCR, cDNA cloning, and sequence comparison of the rat C5L2 with the sequence of other C5L2s}

Since C5L2 is expressed in both mouse and human lungs (26), we chose rat lung for cloning of rat C5L2. Using the mouse C5L2 nucleotide sequence, we designed two oligonucleotides (5'GCTCGGCCGCTCGAGACCATGGACAACCA CACCACCAGC-3' and 5'CCGAAACCGGAATTCCACCGGCAT CTCAGA-3') and PCR amplified an 865 bp cDNA fragment from rat lung. To obtain the full-length coding region of rat C5L2, we performed a BLAST search of the rat EST database using the partial rat C5L2 as the query sequence. One EST clone (dbEST 14223745) was obtained and contained an incomplete sequence of rat C5L2, terminating at the 3 '-end with a poly (A) tail. To isolate sequences extending further upstream, we employed a 5'-RACE approach using a ligation-anchored rat lung cDNA template. A nested pair of primers was designed and two sequential rounds of PCR were carried out using two rat C5L2-specific nested primers in conjunction with adaptor primers. The amplification products of the 5'-RACE reaction were subcloned and sequenced. When the PCR products and the EST sequence were assembled together, we obtained the composite deduced amino acid sequence for C5L2 (Fig. 1A $)$. This sequence was consistent with a full-length coding region based on a comparison with the human and mouse C5L2 sequences and the presence of a putative initiating ATG (Fig. 1, $\underline{A}$ and $\underline{B})$. Two lines of evidence suggested that this ATG was the correct initiation site. First, the 5'-RACE data terminated at the same position in two independent 5'-RACE reactions, with the indicated ATG being the first potential initiation site in the sequence. Second, the sequence surrounding this ATG conforms with the consensus sequence for eukaryotic translation initiation sequences with a purine at position -3 , the most critical residue for translation initiation.

Comparison of the translation of the cDNA with other known C5L2 sequences showed that rat C5L2 is $59.8 \%$ identical to human C5L2 and 86.4\% identical to mouse C5L2 (Fig. 1B). Hydropathy analysis confirmed that the cloned protein has seven transmembrane segments (data not shown). The $\mathrm{N}$ terminus of rat C5L2 contained several acidic amino acids, previously implicated to be a primary site for C5a binding to C5aR $(30,31)$. Like human and mouse C5L2, rat C5L2 did not have the DRY motif present in C5aR, and the third intracellular loop was much shorter than that of $\mathrm{C} 5 \mathrm{aR}$, suggesting that it poorly couples to $\mathrm{G}$ proteins $(26,28)$.

\section{Analysis of rat C5L2 mRNA expression in rat tissues and cells}

We further analyzed the expression of rat C5L2 mRNA in rat tissues using Northern blot analysis (Fig. 1C). Rat C5L2 and C5aR mRNAs were expressed in all tissues examined; while C5L2 mRNA showed highest expression in liver and thyroid, weaker expression was detected in brain, spleen, kidney, large intestine, and eye. In addition, RT-PCR analysis indicated that rat C5L2 mRNA was also present in lung alveolar macrophages and peripheral blood neutrophils (data not shown). To demonstrate cell surface expression of rat C5L2, we transfected a mammalian expression plasmid encoding rat C5L2 into HEK-293 cells and performed confocal fluorescence microscopy analysis. As shown in Fig. 1D, cells transfected with the rat C5L2 demonstrated cell surface expression of C5L2 when $\alpha$ C5L2 was used. 


\section{Comparison of C5L2 expression to C5aR expression in neutrophils during CLP-induced sepsis}

Since recent findings suggest that compromised neutrophil functions during sepsis correlate with the reduction in $\mathrm{C} 5 \mathrm{aR}$ content on neutrophil surfaces (9), we sought to determine if the expression of C5L2 on blood neutrophils was also changed during sepsis. Both C5L2 and C5aR content on rat blood neutrophils were quantitatively evaluated by flow cytometric analysis 0,12 , 24, and $36 \mathrm{~h}$ after the onset of CLP. As shown in Fig. 2A, blood neutrophils from control animals (time 0) showed positive staining for both C5L2 and C5aR. During experimental sepsis, C5L2 content on blood neutrophils was significantly increased 24 and $36 \mathrm{~h}$ after onset of CLP. In contrast, C5aR content on neutrophils significantly dropped (2.5-fold) $24 \mathrm{~h}$ after CLP and steadily increased thereafter, suggesting that surface C5L2 and C5aR may be independently regulated in blood neutrophils during sepsis.

To determine the mechanism by which C5L2 content on neutrophils is regulated during sepsis, we evaluated C5L2 mRNA levels in purified neutrophils 0, 24, and $36 \mathrm{~h}$ after CLP. As shown in Fig. $2 B$, the C5L2 mRNA level dramatically increased 24 and $36 \mathrm{~h}$ after the onset of CLP, suggesting a transcriptional mechanism was involved in increased expression of C5L2. In contrast, $\mathrm{C} 5 \mathrm{aR}$ mRNA levels showed no differences in blood neutrophils isolated at various time points after CLP (Fig. 2B).

To visualize C5L2 changes in neutrophils during sepsis, we conducted confocal fluorescence microscopy analysis. As shown in Fig. 2C, in control cells both C5aR and C5L2 showed a uniform cortical pattern on the neutrophil periphery, indicative of membrane staining. In contrast, a diffuse pattern of staining was found in the cytoplasmic compartment in $24 \mathrm{~h}$ CLP neutrophils for $\mathrm{C} 5 \mathrm{aR}$, but not for $\mathrm{C} 5 \mathrm{~L} 2$, indicating that $\mathrm{C} 5 \mathrm{~L} 2$ did not undergo internalization as C5aR after CLP.

\section{Changed in vivo organ binding of ${ }^{125} \mathrm{I}-\alpha \mathrm{C} 5 \mathrm{~L} 2$ during CLP-induced sepsis in mice}

Our previous work indicated up-regulation of $\mathrm{C} 5 \mathrm{aR}$ protein in mouse lung, liver, heart, and kidney after CLP (24). To examine changes in C5L2 expression during sepsis, ${ }^{125} \mathrm{I}-\alpha \mathrm{C} 5 \mathrm{~L} 2$ (4 $\mu \mathrm{Ci}),{ }^{125} \mathrm{I}-\alpha \mathrm{C} 5 \mathrm{aR}(2 \mu \mathrm{Ci})$, or ${ }^{125} \mathrm{I}$-preimmune $\mathrm{IgG}(2 \mu \mathrm{Ci})$ were injected intravenously into mice at various time points (up to $12 \mathrm{~h}$ ) after CLP. Total amounts of protein infused were $100 \mathrm{ng}$ for $\alpha \mathrm{C} 5 \mathrm{aR}$ and $\alpha \mathrm{C} 5 \mathrm{~L} 2$ and $2 \mu \mathrm{g}$ for normal rabbit IgG. Details of this technique are described elsewhere (24). As shown in Fig. $3, \underline{A}$ and $\underline{B}$, each of the four organs, with the exception of C5L2 in kidney showed increases in both C5aR and C5L2 content $12 \mathrm{~h}$ after CLP when compared with levels at time 0 . In all but one case, the peak increases were at $12 \mathrm{~h}$ when compared with 3 and 6 $\mathrm{h}$ after CLP (data not shown). In each case except the kidney, the increases at $12 \mathrm{~h}$ were statistically significant $(P<0.05)$. In kidney, the peak increase, which was statistically significant, in C5L2 occurred at $3 \mathrm{~h}$ (data not shown). In all cases, the infusion of ${ }^{125} \mathrm{I}$-preimmune IgG at 0 , 3, 6, and $12 \mathrm{~h}$ after CLP showed no evidence of increased tissue localization (Fig. 3C). These data indicate that sepsis causes increases in both C5aR and C5L2 in organs that are targets of multi-organ failure (8). 


\section{Expression of mRNA for C5L2 during CLP-induced sepsis}

To extend the results from the in vivo binding experiments, we conducted quantitative real-time PCR experiments using RNA extracts from mouse organs. As shown in Fig. 4A, in each of the four organs studied, there was an increase in the amount of mRNA for C5aR during the CLPinduced sepsis, roughly correlating with increased organ binding of ${ }^{125} \mathrm{I}-\alpha \mathrm{C} 5 \mathrm{aR}$ (Fig. $\left.3 \mathrm{~A}\right)$. In the lung and liver, an increased mRNA for C5L2 in the real-time PCR was only observed $12 \mathrm{~h}$ after CLP (Fig. 4B). In kidney and heart, there was no significantly increased level of C5L2 mRNA observed after the onset of CLP (Fig. 4B). These results suggested that the dynamic pattern of ${ }^{125} \mathrm{I}-\alpha \mathrm{C} 5 \mathrm{~L} 2$ binding to the various organs during sepsis may not solely be explained by an increased gene expression for C5L2 in these organs.

\section{Effects of $\alpha \mathrm{C5aR}$ and $\alpha \mathrm{C5L} 2$ on in vitro and in vivo production of IL-6}

Recent work from our laboratory (32) has shown that the co-presence of C5a with LPS induced enhanced production of IL-6 in blood neutrophils. To investigate the role of C5aR and C5L2 on IL-6 production, we conducted in vitro experiments with blood neutrophils obtained from healthy rats. As shown in Fig. 5A, C5a significantly augmented LPS-induced robust production of IL-6 in the presence of normal IgG. When neutrophils were preincubated with $\alpha \mathrm{C} 5 \mathrm{aR} \mathrm{IgG,}$ the augmentation in IL-6 production related to costimulation with C5a disappeared. In dramatic contrast, neutrophil exposure to $\alpha \mathrm{C} 5 \mathrm{~L} 2$ IgG dramatically increased production of IL-6 in neutrophils exposed to both LPS and C5a. To further extend these results, we measured IL-6 levels in serum samples obtained $6 \mathrm{~h}$ after CLP in mice treated intravenously with preimmune $\mathrm{IgG}, \alpha \mathrm{C} 5 \mathrm{aR}$, or C5L2 IgG. The results are shown in Fig. 5B. As expected, serum IL-6 was elevated in mice $6 \mathrm{~h}$ after CLP. In $\alpha \mathrm{C} 5 \mathrm{aR}$-treated mice, IL-6 levels were reduced to nearly undetectable levels $6 \mathrm{~h}$ after CLP when compared with control IgG-injected mice. In striking contrast, $\alpha$ C5L2-treated mice dramatically increased (by nearly fourfold) serum levels of IL-6, suggesting that there may be competition between C5aR and C5L2 for C5a binding, the balance determining serum levels of IL-6 during sepsis. Taken together, these results demonstrate that C5L2 may act as a high affinity decoy receptor, competing for C5a binding, to limit the inflammatory response caused by $\mathrm{C} 5 \mathrm{a}$ interaction with $\mathrm{C} 5 \mathrm{aR}$.

\section{DISCUSSION}

The CLP model of sepsis in rodents closely reflects the clinical phases found in humans with sepsis, with an early hyperdynamic phase (tachycardia, increased cardiac output, and respiration, fever, leukocytosis, etc.) and a late hypodynamic phase (bradycardia, reduced cardiac output, hypothermia, leucopenia, etc.), (32) There is strong evidence for the adverse role of C5a in sepsis (33). Although much progress has been made in understanding the role of C5a and its receptor $\mathrm{C} 5 \mathrm{aR}$ in sepsis, the many types of cells that can respond to C5a suggests that a multitude of biological responses may be triggered during sepsis. Recently, a second receptor for C5a, C5L2, was cloned from human and mouse $(26,28,29)$, but its biological function is quite unclear. In this study, we report the cloning of rat C5L2 and describe changes in the expression and function of C5L2 in the setting of sepsis. The deduced amino acid sequence of this receptor is 59.8\% identical to human C5L2 and 86.4\% identical to mouse C5L2. Hydropathy analysis confirmed that the cloned protein has seven transmembrane segments (data not shown). As is the case for C5aR, C5L2 has an acidic ligand binding N-terminal domain and a ligand activation domain. 
The substitution of leucine for arginine in the DRY sequence at the end of the third transmembrane segment in rat C5L2 and a shorter third intracellular loop devoid of Ser/Thr residues were found in rat C5L2, similar to human and mouse C5L2 $(26,28)$, suggesting this receptor does not mediate C5a signaling in rats. Northern blot and RT-PCR analysis of mRNA prepared from various tissues and myeloid cells revealed that C5L2 was expressed in a variety of rat tissues, in rat blood neutrophils, and in alveolar macrophages. The concordant expression pattern of $\mathrm{C} 5 \mathrm{~L} 2$ and $\mathrm{C} 5 \mathrm{aR}$ mRNA suggests that C5L2 might exist as a binding protein competing with $\mathrm{C} 5 \mathrm{aR}$ for C5a binding.

Our recent work has shown that during the onset of CLP-induced sepsis, C5aR content on blood neutrophils significantly drops, reaching the lowest point at $24 \mathrm{~h}$ after CLP, presumably due to ligand-receptor internalization (9). Correspondingly, innate immune functions such as chemotaxis and the oxidative burst of neutrophils were substantially impaired (9). Beyond $24 \mathrm{~h}$ after CLP, blood neutrophils started to undergo a functional recovery, correlating with increased surface C5aR expression (9). In the current study, we demonstrate that C5L2 content on blood neutrophils significantly increases between 24 and $36 \mathrm{~h}$ after onset of CLP, suggesting that expression of C5L2 on blood neutrophils during sepsis is regulated differently from that of $\mathrm{C} 5 \mathrm{aR}$. It is well established that interaction of $\mathrm{C} 5 \mathrm{a}$ with $\mathrm{C} 5 \mathrm{aR}$ leads to rapid internalization of the receptor-ligand complex because of phosphorylation of serine residues of the receptor, while dephosphorylation of the receptor results its being recycled back to the surface of the cell (3436). Although excessive C5a appears to be produced during sepsis, the lack of phosphorylation of C5L2 after contact with C5a may be linked to the absence of internalization of the C5a/C5L2 complex $(26,28)$. Our previous study demonstrated that neutrophils from 24 and $48 \mathrm{~h}$ CLP rats showed a nearly $400 \%$ increase in the surface content of C5a (10). Basing on this result and our current findings, it is possible that the substantial amounts of C5a on the surface of blood neutrophils during sepsis are due to C5a binding in a stationary manner to surface C5L2.

We recently reported an increased in vivo binding of $\alpha \mathrm{C} 5 \mathrm{aR}$ and accompanying increased expression of mRNA for C5aR in mouse lung, liver, kidney, and heart after CLP-induced sepsis (24). We now report that the in vivo binding of $\alpha \mathrm{C} 5 \mathrm{~L} 2$ was significantly increased in mouse lung, liver, and heart, but not kidney, $12 \mathrm{~h}$ after CLP when compared with levels at time 0 . This suggests increases in C5L2 in multiple organs during sepsis. In addition, real-time PCR experiments showed dramatically increased mRNA expression for C5L2 in mouse liver and lung during sepsis. The biological implications of changes in C5a receptors during sepsis are not currently known but may be linked to development of multi-organ failure. Furthermore, whether the regulation of $\mathrm{C} 5 \mathrm{~L} 2$ expression in the different organs during sepsis is similar to that in neutrophils remains to be defined. Since it has been shown in an animal model of CLP-induced sepsis that lungs, liver, heart, and kidneys are targets for development of multiorgan failure, and blocking of C5a reduces the intensity of multi-organ failure (8), it is of great interest to explore if C5L2 plays a functional role in these organs during sepsis.

Finally, we provide evidence that exposure of rat neutrophils to C5a and LPS results in dramatically increased release of IL-6 in the presence of $\alpha$ C5L2 (Fig. 5A). In contrast, blockade of C5aR significantly reduces in vitro IL-6 levels after cell stimulation by C5a and LPS. Furthermore, mice injected with $\alpha$ C5L2 at the start of CLP show dramatically increased serum levels of IL-6 when compared with control animals receiving nonspecific IgG. In contrast, serum levels of IL-6 are reduced to nearly undetectable levels in $\alpha \mathrm{C} 5 \mathrm{aR}$-treated mice (Fig. $5 B)$. These 
results, coupled with our finding that there is increased surface expression of C5L2 on neutrophils during sepsis, suggest that C5L2 may have important functional roles during inflammatory events, behaving as a decoy (or scavenger) receptor for C5a, thereby limiting the inflammatory response caused by $\mathrm{C} 5 \mathrm{a}$ binding to $\mathrm{C} 5 \mathrm{aR}$.

Taken together, our results indicate that there is significantly increased expression of C5L2 (and C5aR) in lung, liver, kidney, and heart during CLP-induced sepsis in mice. Surface expression of C5L2 on blood neutrophils is also significantly increased during sepsis. Significantly amplified production of IL-6 occurs in vitro in neutrophils stimulated with C5a and LPS. After C5L2 blockade in CLP mice, IL-6 levels are dramatically elevated. These data strongly suggest that, depending on the relative numbers of $\mathrm{C} 5 \mathrm{aR}$ and $\mathrm{C} 5 \mathrm{~L} 2$, the generation of $\mathrm{C} 5 \mathrm{a}$ may lead to an amplified pro-inflammatory response or a suppressed proinflammatory response.

\section{ACKNOWLEDGMENTS}

This work is supported by National Institute of Health Grant GM-29507. The authors wish to thank Beverly Schumann for assistance in the preparation of this paper.

\section{REFERENCES}

1. Ward, P. A. (2004) The dark side of C5a in sepsis. Nat. Rev. Immunol. 4, 133-142

2. Riedemann, N. C., Guo, R. F., and Ward, P. A. (2003) Novel strategies for the treatment of sepsis. Nat. Med. 9, 517-524

3. Cochrane, C. G., and Muller-Eberhard, H. J. (1968) The derivation of two distinct anaphylatoxin activities from the third and fifth components of human complement. J. Exp. Med. 127, 371-386

4. Goldstein, I. M., and Weissmann, G. (1974) Generation of C5-derived lysosomal enzymereleasing activity (C5a) by lysates of leukocyte lysosomes. J. Immunol. 113, 1583-1588

5. Sacks, T., Moldow, C. F., Craddock, P. R., Bowers, T. K., and Jacob, H. S. (1978) Oxygen radicals mediate endothelial cell damage by complement- stimulated granulocytes. An in vitro model of immune vascular damage. J. Clin. Invest. 61, 1161-1167

6. Schumacher, W. A., Fantone, J. C., Kunkel, S. E., Webb, R. C., and Lucchesi, B. R. (1991) The anaphylatoxins $\mathrm{C} 3 \mathrm{a}$ and $\mathrm{C} 5 \mathrm{a}$ are vasodilators in the canine coronary vasculature in vitro and in vivo. Agents Actions 34, 345-349

7. Shin, H. S., Snyderman, R., Friedman, E., Mellors, A., and Mayer, M. M. (1968) Chemotactic and anaphylatoxic fragment cleaved from the fifth component of guinea pig complement. Science 162, 361-363

8. Huber-Lang, M., Sarma, V. J., Lu, K. T., McGuire, S. R., Padgaonkar, V. A., Guo, R. F., Younkin, E. M., Kunkel, R. G., Ding, J., Erickson, R., et al. (2001) Role of C5a in multiorgan failure during sepsis. J. Immunol. 166, 1193-1199 
9. Guo, R. F., Riedemann, N. C., Bernacki, K. D., Sarma, V. J., Laudes, I. J., Reuben, J. S., Younkin, E. M., Neff, T. A., Paulauskis, J. D., Zetoune, F. S., et al. (2003) Neutrophil C5a receptor and the outcome in a rat model of sepsis. FASEB J. 17, 1889-1891

10. Czermak, B. J., Sarma, V., Pierson, C. L., Warner, R. L., Huber-Lang, M., Bless, N. M., Schmal, H., Friedl, H. P., and Ward, P. A. (1999) Protective effects of C5a blockade in sepsis. Nat. Med. 5, 788-792

11. Huber-Lang, M. S., Younkin, E. M., Sarma, J. V., McGuire, S. R., Lu, K. T., Guo, R. F., Padgaonkar, V. A., Curnutte, J. T., Erickson, R., and Ward, P. A. (2002) Complementinduced impairment of innate immunity during sepsis. J. Immunol. 169, 3223-3231

12. Stevens, J. H., O'Hanley, P., Shapiro, J. M., Mihm, F. G., Satoh, P. S., Collins, J. A., and Raffin, T. A. (1986) Effects of anti-C5a antibodies on the adult respiratory distress syndrome in septic primates. J. Clin. Invest. 77, 1812-1816

13. Hangen, D. H., Stevens, J. H., Satoh, P. S., Hall, E. W., O'Hanley, P. T., and Raffin, T. A. (1989) Complement levels in septic primates treated with anti-C5a antibodies. J. Surg. Res. 46, 195-199

14. Gerard, N. P., Hodges, M. K., Drazen, J. M., Weller, P. F., and Gerard, C. (1989) Characterization of a receptor for C5a anaphylatoxin on human eosinophils. J. Biol. Chem. 264, 1760-1766

15. Gerard, N. P., and Gerard, C. (1991) The chemotactic receptor for human C5a anaphylatoxin. Nature 349, 614-617

16. Zwirner, J., Fayyazi, A., and Gotze, O. (1999) Expression of the anaphylatoxin C5a receptor in non-myeloid cells. Mol. Immunol. 36, 877-884

17. Haviland, D. L., McCoy, R. L., Whitehead, W. T., Akama, H., Molmenti, E. P., Brown, A., Haviland, J. C., Parks, W. C., Perlmutter, D. H., and Wetsel, R. A. (1995) Cellular expression of the $\mathrm{C} 5 \mathrm{a}$ anaphylatoxin receptor $(\mathrm{C} 5 \mathrm{aR})$ : demonstration of $\mathrm{C} 5 \mathrm{aR}$ on nonmyeloid cells of the liver and lung. J. Immunol. 154, 1861-1869

18. Floreani, A. A., Heires, A. J., Welniak, L. A., Miller-Lindholm, A., Clark-Pierce, L., Rennard, S. I., Morgan, E. L., and Sanderson, S. D. (1998) Expression of receptors for C5a anaphylatoxin (CD88) on human bronchial epithelial cells: enhancement of C5a-mediated release of IL-8 upon exposure to cigarette smoke. J. Immunol. 160, 5073-5081

19. Schieferdecker, H. L., Schlaf, G., Koleva, M., Gotze, O., and Jungermann, K. (2000) Induction of functional anaphylatoxin $\mathrm{C} 5 \mathrm{a}$ receptors on hepatocytes by in vivo treatment of rats with IL-6. J. Immunol. 164, 5453-5458

20. Wetsel, R. A. (1995) Expression of the complement C5a anaphylatoxin receptor (C5aR) on non- myeloid cells. Immunol. Lett. 44, 183-187 
21. Gasque, P., Singhrao, S. K., Neal, J. W., Gotze, O., and Morgan, B. P. (1997) Expression of the receptor for complement C5a (CD88) is up-regulated on reactive astrocytes, microglia, and endothelial cells in the inflamed human central nervous system. Am. J. Pathol. 150, 3141

22. Chenoweth, D. E., and Hugli, T. E. (1978) Demonstration of specific C5a receptor on intact human polymorphonuclear leukocytes. Pro. Natl. Acad. Sci. USA. 75, 3943-3947

23. Nataf, S., Davoust, N., Ames, R. S., and Barnum, S. R. (1999) Human T cells express the C5a receptor and are chemoattracted to C5a. J. Immunol. 162, 4018-4023

24. Riedemann, N. C., Guo, R. F., Neff, T. A., Laudes, I. J., Keller, K. A., Sarma, V. J., Markiewski, M. M., Mastellos, D., Strey, C. W., Pierson, C. L., et al. (2002) Increased C5a receptor expression in sepsis. J. Clin. Invest. 110, 101-108

25. Huber-Lang, M. S., Sarma, J. V., McGuire, S. R., Lu, K. T., Guo, R. F., Padgaonkar, V. A., Younkin, E. M., Laudes, I. J., Riedemann, N. C., Younger, J. G., et al. (2001) Protective effects of anti-C5a peptide antibodies in experimental sepsis. FASEB J. 15, 568-570

26. Okinaga, S., Slattery, D., Humbles, A., Zsengeller, Z., Morteau, O., Kinrade, M. B., Brodbeck, R. M., Krause, J. E., Choe, H. R., Gerard, N. P., et al. (2003) C5L2, a nonsignaling C5A binding protein. Biochemistry 42, 9406-9415

27. Kalant, D., Cain, S. A., Maslowska, M., Sniderman, A. D., Cianflone, K., and Monk, P. N. (2003) The chemoattractant receptor-like protein C5L2 binds the C3a des-Arg77/acylationstimulating protein. J. Biol. Chem. 278, 11123-11129

28. Cain, S. A., and Monk, P. N. (2002) The orphan receptor C5L2 has high affinity binding sites for complement fragments C5a and C5a des-Arg(74). J. Biol. Chem. 277, 7165-7169

29. Ohno, M., Hirata, T., Enomoto, M., Araki, T., Ishimaru, H., and Takahashi, T. A. (2000) A putative chemoattractant receptor, C5L2, is expressed in granulocyte and immature dendritic cells, but not in mature dendritic cells. Mol. Immunol. 37, 407-412

30. Farzan, M., Schnitzler, C. E., Vasilieva, N., Leung, D., Kuhn, J., Gerard, C., Gerard, N. P., and Choe, H. (2001) Sulfated tyrosines contribute to the formation of the C5a docking site of the human C5a anaphylatoxin receptor. J. Exp. Med. 193, 1059-1066

31. Morgan, E. L., Ember, J. A., Sanderson, S. D., Scholz, W., Buchner, R., Ye, R. D., and Hugli, T. E. (1993) Anti-C5a receptor antibodies. Characterization of neutralizing antibodies specific for a peptide, C5aR-(9-29), derived from the predicted amino-terminal sequence of the human C5a receptor. J. Immunol. 151, 377-388

32. Riedemann, N. C., Guo, R. F., Hollmann, T. J., Gao, H., Neff, T. A., Reuben, J. S., Speyer, C. L., Sarma, J. V., Wetsel, R. A., et al. (2004) Regulatory role of C5a in LPS-induced IL-6 production by neutrophils during sepsis. FASEB J. 18, 370-372. 
33. Ward, P. A., Riedemann, N. C., Guo, R. F., Huber-Lang, M., Sarma, J. V. and Zetoune, F. S. (2003) Anti-complement strategies in experimental sepsis. Scand. J. Infect. Dis. 35, 601603.

34. Naik, N., Giannini, E., Brouchon, L., and Boulay, F. (1997) Internalization and recycling of the C5a anaphylatoxin receptor: evidence that the agonist-mediated internalization is modulated by phosphorylation of the C-terminal domain. J. Cell Sci. 110, 2381-2390.

35. Giannini, E., and Boulay, F. (1995) Phosphorylation, dephosphorylation, and recycling of the C5a receptor in differentiated HL60 cells. J. Immunol. 154, 4055-4064.

36. Van Epps, D. E., Simpson, S., Bender, J. G., and Chenoweth, J. E.. (19900. Regulation of $\mathrm{C} 5 \mathrm{a}$ and formyl peptide receptor expression on human polymorphonuclear leukocytes. $J$. Immunol. 144,1062-1068.

Received November 19, 2004; accepted February 1, 2005. 
Fig. 1

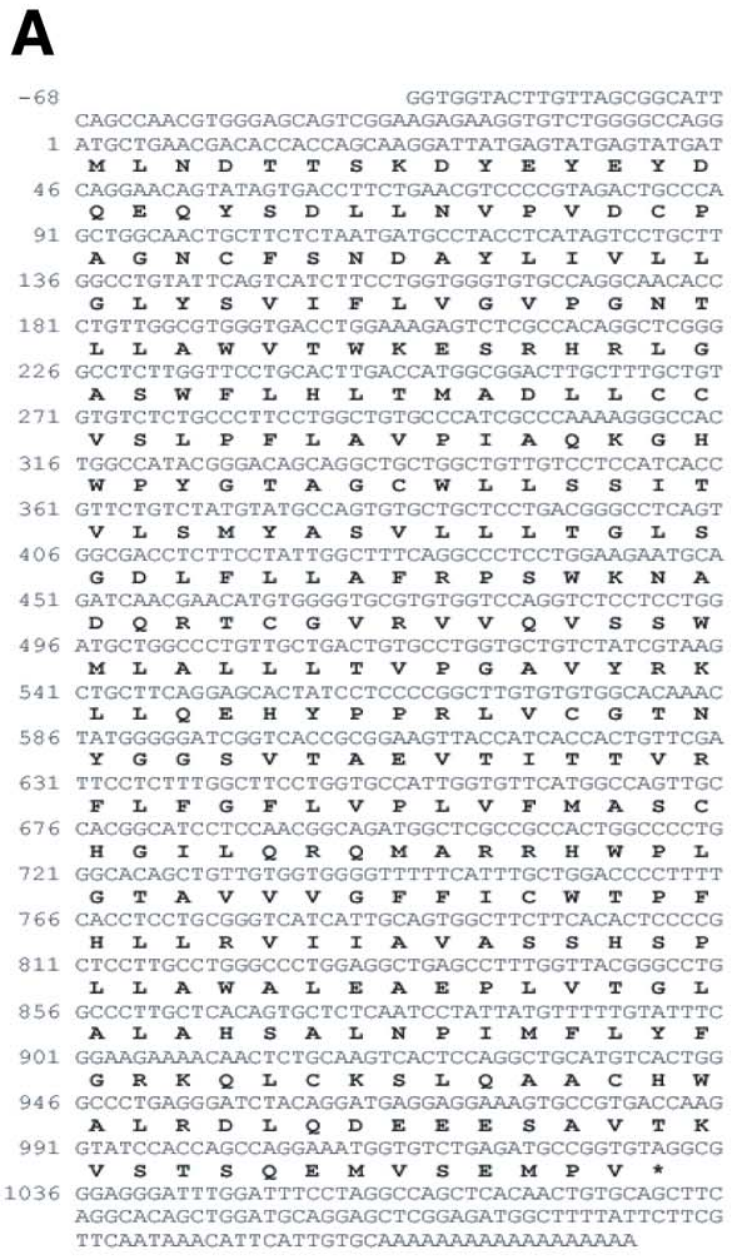

B

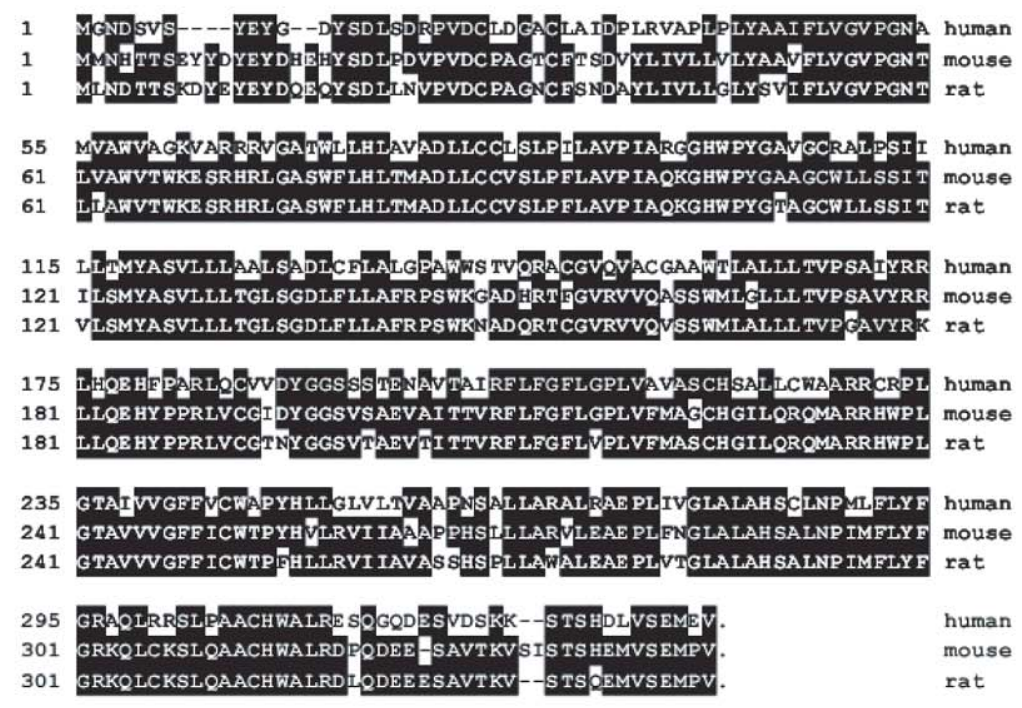

C

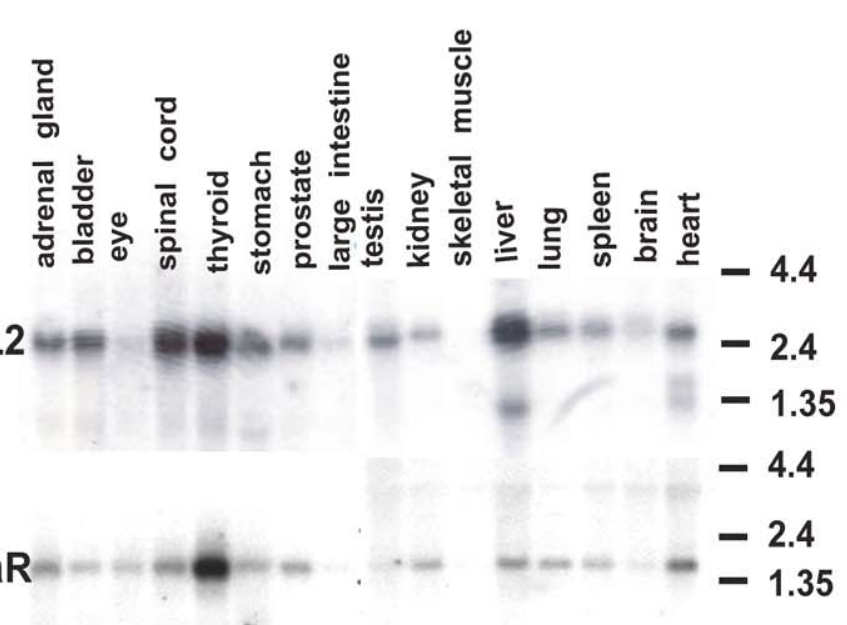

\section{Immunofluorescence localization}

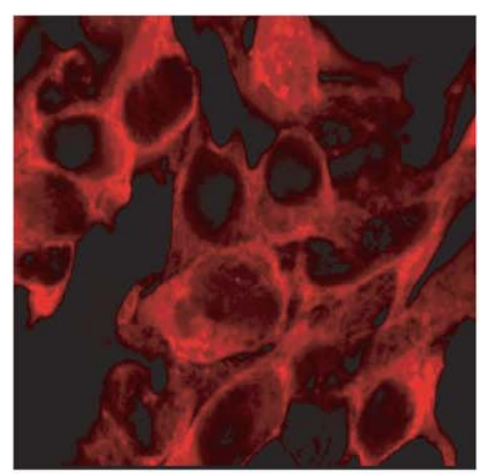

Figure 1. Characteristics of rat C5L2. A) Deduced rat C5L2 open reading frame, which encodes a protein of 343 amino acids. B) Comparison of rat C5L2 to mouse and human C5L2 sequences. Black shaded areas indicate identity. $\boldsymbol{C}$ ) Northern blot analysis of rat C5L2 and C5aR expression in various tissues. D) Cell surface expression of rat C5L2 in transiently transfected HEK 293 cells, as visualized by confocal microscopy. Rat C5L2 sequence data are available from GenBank/EMBL/DDBJ under accession no. AY600435. 
Fig. 2

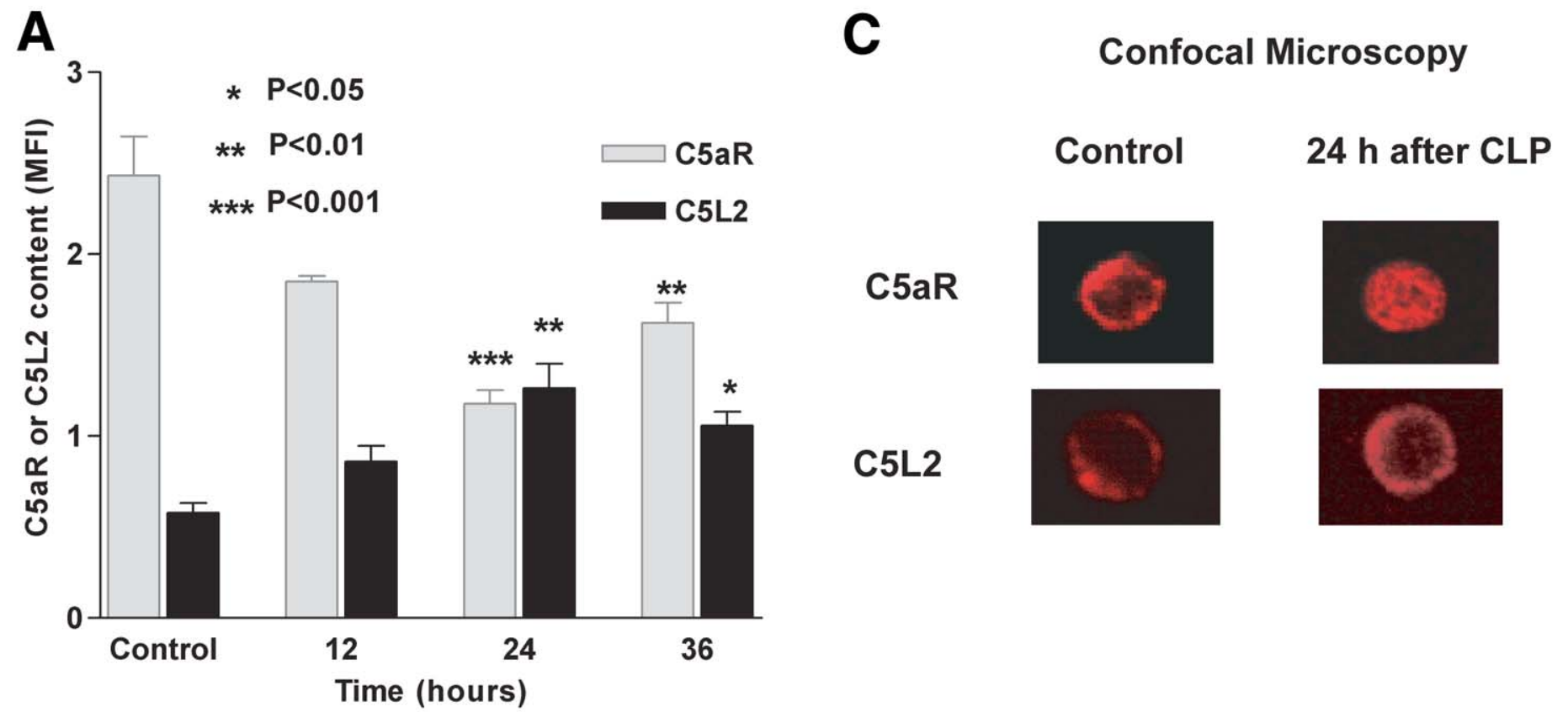

B

\section{Rat blood neutrophil}

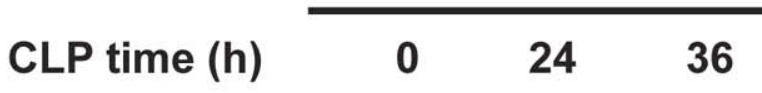

C5L2

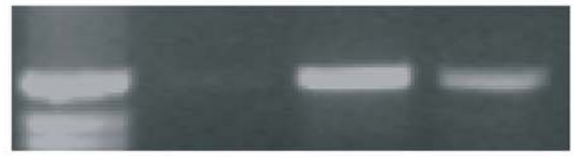

C5aR

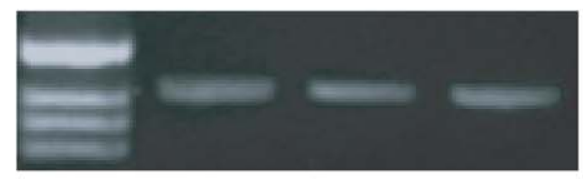

GAPDH

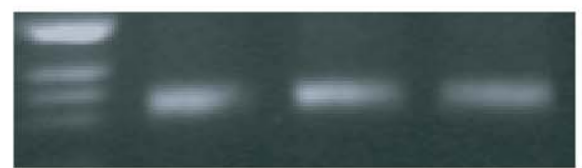

Figure 2. Expression of C5L2 and C5aR on neutrophils during experimental sepsis. A) Whole blood samples from controls (normal rats) and CLP animals were stained with $\alpha \mathrm{C} 5 \mathrm{~L} 2$ or $\alpha \mathrm{C} 5 \mathrm{aR}$ rabbit serum or pre-immune serum, and C5L2 and $\mathrm{C} 5 \mathrm{aR}$ content on blood neutrophils was evaluated by flow cytometric analysis at times indicated. Error bars are means \pm SE $(n=4-6)$. B) RT-PCR for C5L2 and C5aR mRNA in rat blood neutrophils. RT-PCR was performed using total RNA from rat neutrophils isolated 0,24, and $36 \mathrm{~h}$ after CLP. Equal loading of PCR product, as demonstrated by expression of GAPDH mRNA. Data represent 2 independent experiments with neutrophils pooled from 3-4 rats per time point. $C$ ) C5aR and C5L2 staining of blood neutrophils, as visualized by confocal microscopy. 
Fig. 3

A $\alpha$ C5aR Lung
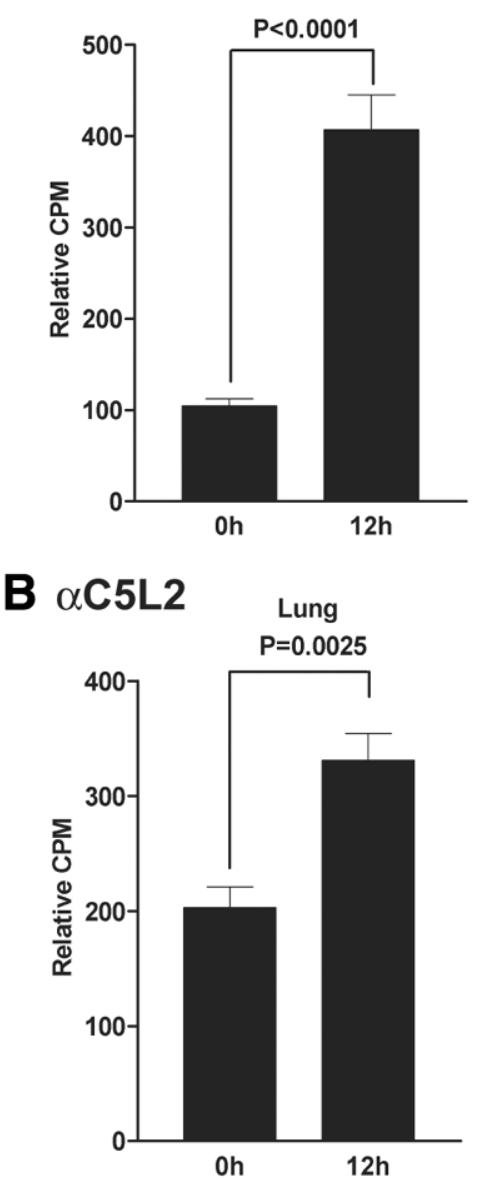

\section{Normal IgG}

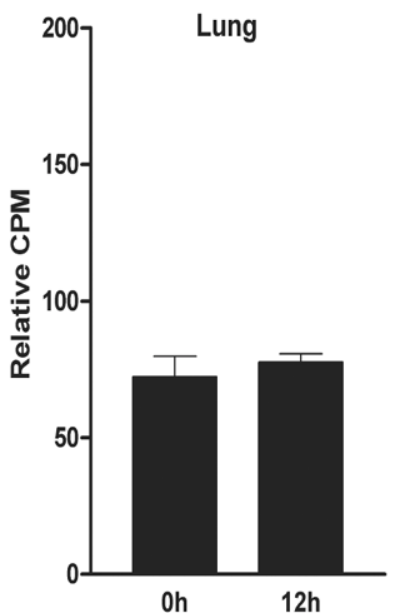

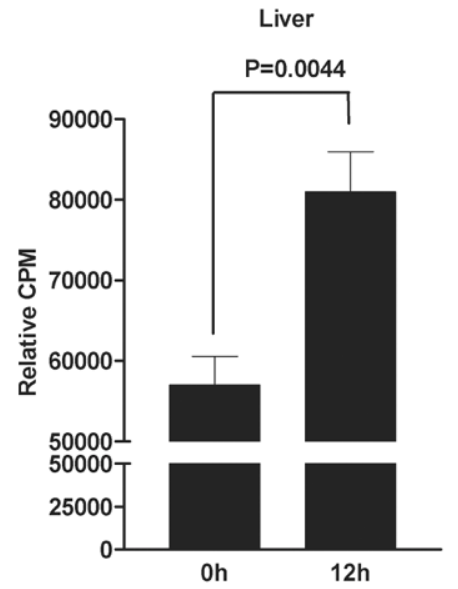
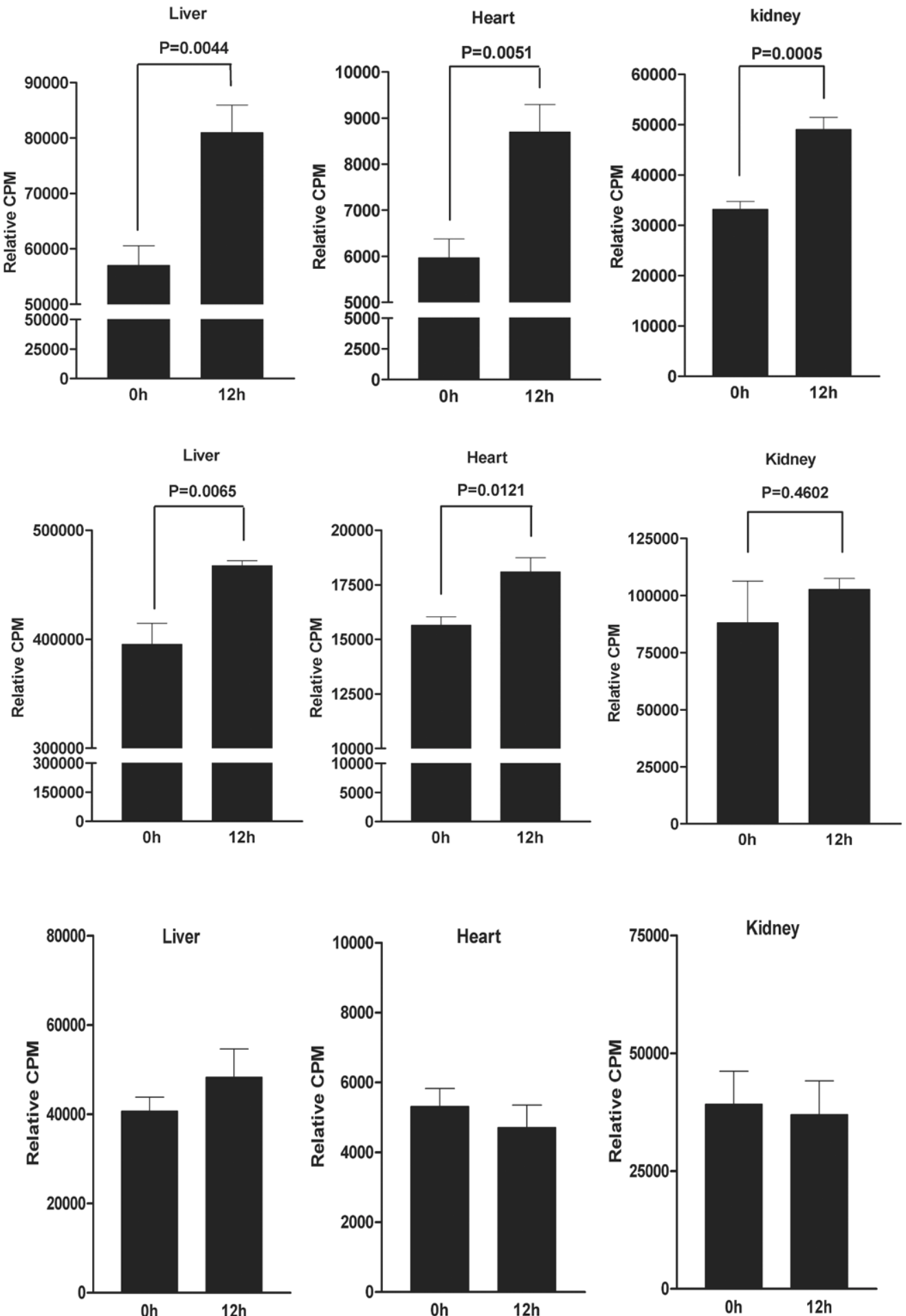

Figure 3. In vivo binding of $(\boldsymbol{A}){ }^{125} \mathrm{I}-\alpha \mathrm{C} 5 \mathrm{aR}$ and $(\boldsymbol{B}){ }^{125} \mathrm{I}-\alpha \mathrm{C} 5 \mathrm{~L} 2$ to organs 0 and $12 \mathrm{~h}$ after CLP. Binding is expressed as the ratio of counts per min (CPM) per gram organ from each animal obtained 15 min after intravenous injection of ${ }^{125} \mathrm{I}$ $\alpha \mathrm{C} 5 \mathrm{aR}$ or ${ }^{125} \mathrm{I}-\alpha \mathrm{C} 5 \mathrm{~L} 2 . C$ ) In vivo binding of ${ }^{125} \mathrm{I}$-labeled pre-immune rabbit IgG to organs after CLP (data expressed in a similar way as in frames $\boldsymbol{A}$ and $\boldsymbol{B})$. Error bars are means \pm SE (n=4-5). 
Fig. 4
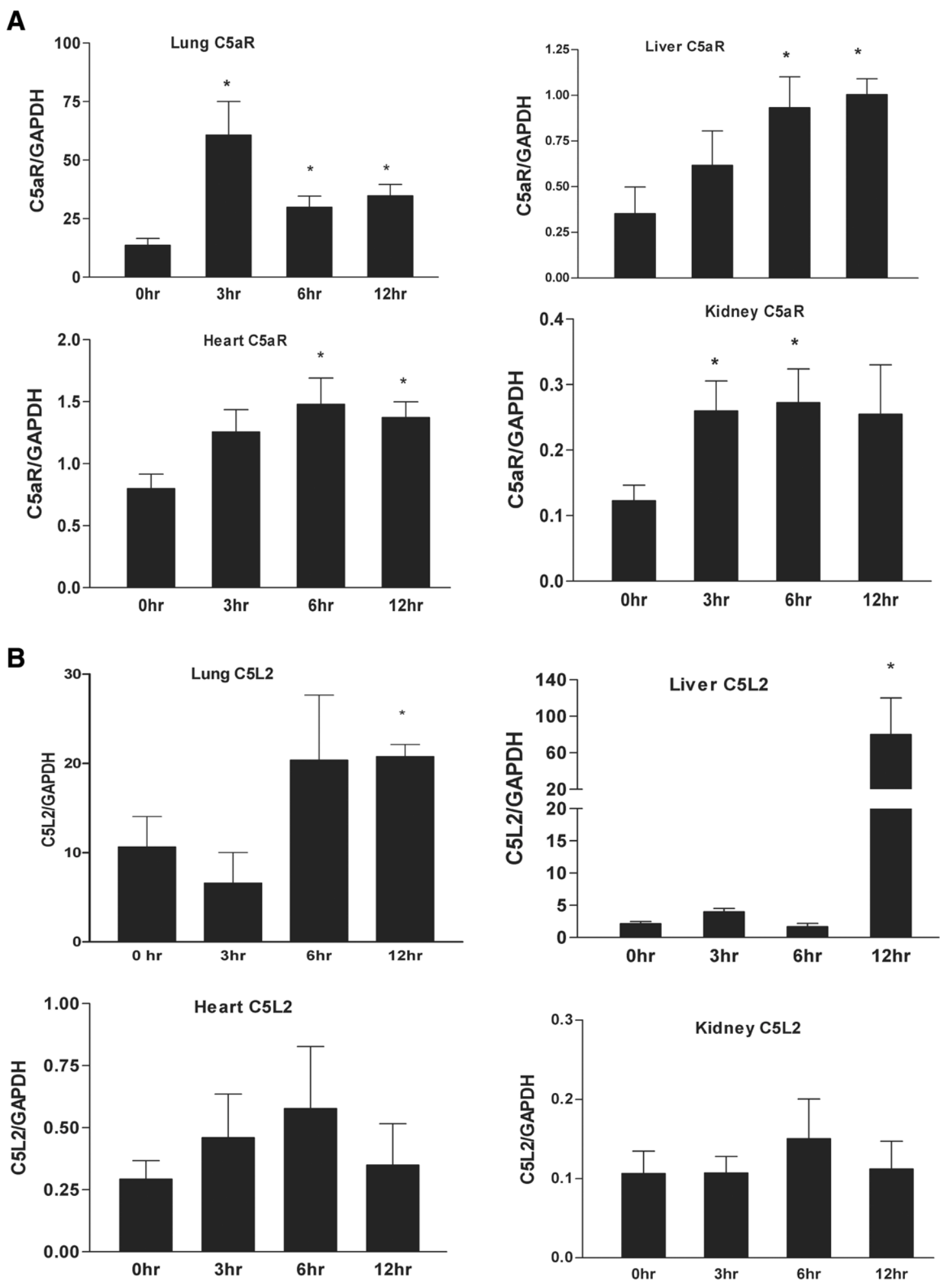

Figure 4. Real-time PCR for C5aR $(\boldsymbol{A})$ and C5L2 (B) mRNA in mouse lung, liver, kidney, and heart. PCR was performed using RNA isolated 0, 3, 6, and $12 \mathrm{~h}$ after CLP. Results were expressed as a ratio to GADPH and represent 3-6 animals for each time point. *Statistical significance in treated groups when compared with control animals. 
Fig. 5
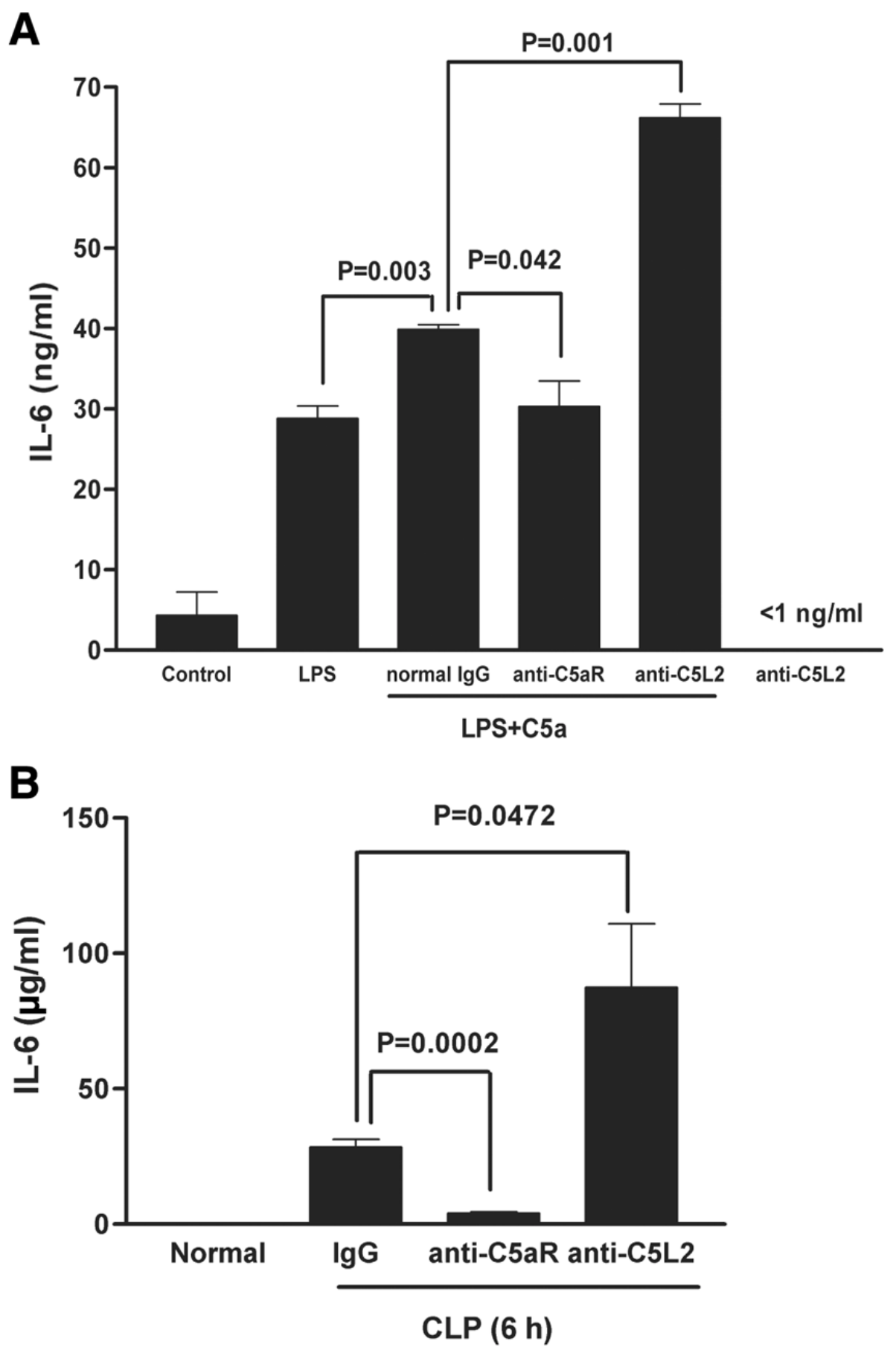

Treatment

Figure 5. Effects of $\alpha \mathrm{C} 5 \mathrm{~L} 2$ and $\alpha \mathrm{C} 5 \mathrm{aR}$ on in vitro production of IL-6 by blood neutrophils stimulated in vitro with LPS + C5a and serum levels of IL-6 $6 \mathrm{~h}$ after CLP in rats treated with blocking antibodies to C5aR or C5L2. A) IL-6 as measured by ELISA analysis in supernatant fluids from blood neutrophils after in vitro incubation with C5a (10 nM) or LPS (20 $\mathrm{ng} / \mathrm{ml}$ ) in the presence or absence of $\alpha \mathrm{C} 5 \mathrm{~L} 2$ or $\alpha \mathrm{C} 5 \mathrm{aR}$. Neutrophils were pooled from 4-6 animals per study; incubations were carried out in separate triplicate samples. B) ELISA measurements for serum IL-6 levels $6 \mathrm{~h}$ after CLP-induced sepsis in animals injected with $\alpha \mathrm{C} 5 \mathrm{~L} 2, \alpha \mathrm{C} 5 \mathrm{aR}$, or pre-immune IgG. IL-6 could not be detected in sera from control (normal) mice. When used, $\alpha \mathrm{C} 5 \mathrm{~L} 2$ and $\alpha \mathrm{C} 5 \mathrm{aR}$ treatment consisted of $20 \mu \mathrm{g} / \mathrm{mouse}$ at the start of CLP, with a companion group treated with control IgG. Error are means $\pm \operatorname{SE}(n=4)$. 